\title{
Background Oriented Schlieren (BOS) of a Supersonic Aircraft in Flight
}

\author{
James T. Heineck, NASA Ames \\ Daniel W. Banks, NASA Armstrong \\ Edward T. Schairer, NASA Ames \\ Edward A. Haering, Jr., NASA Armstrong \\ Paul S. Bean, NASA Armstrong
}

AIAA Flight Test Conference

June 13-17, 2016

Washington, DC 


\section{Introduction}

- Schlieren imaging for aerodynamics research was limited to ground test facilities

- Weinstein introduced the first reliable method for flight test in 1994

- Retroreflective Background Oriented Schlieren was demonstrated to work for full-scale aircraft in flight in 2012 (DLR Goettingen)

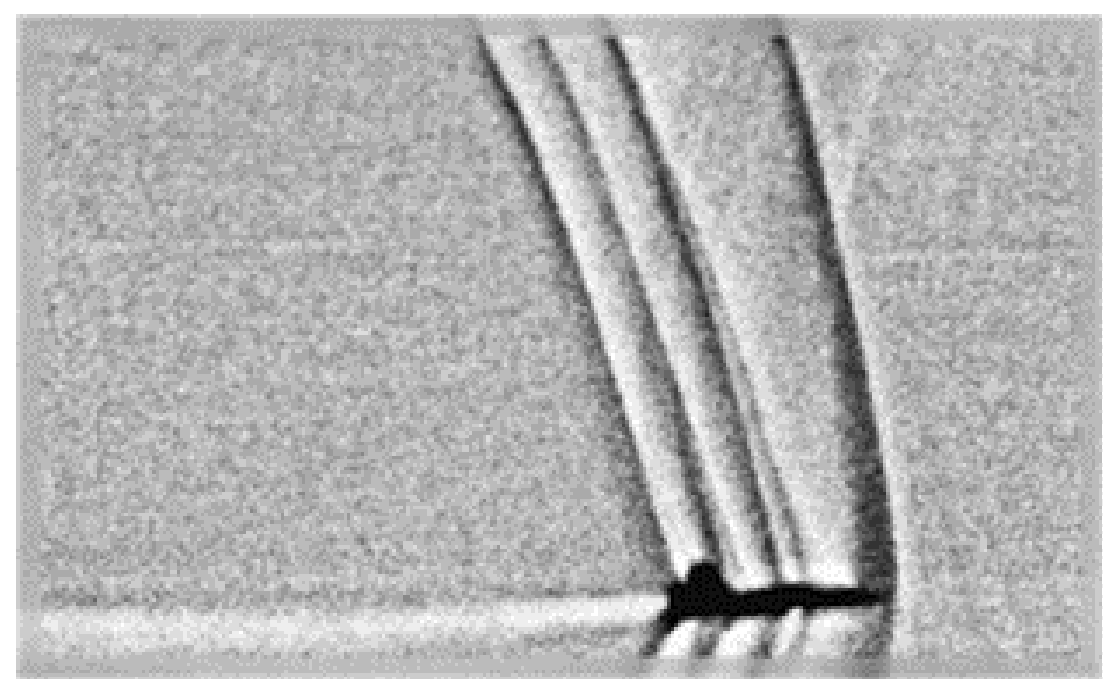

Weinstein's sun-edge streak camera image of a T-38

- NASA's Commercial Supersonic Technology Program developed the next generation airborne schlieren methods for supersonic flight testing. First AirBOS flight in April, 2011 was successful, but restricted.

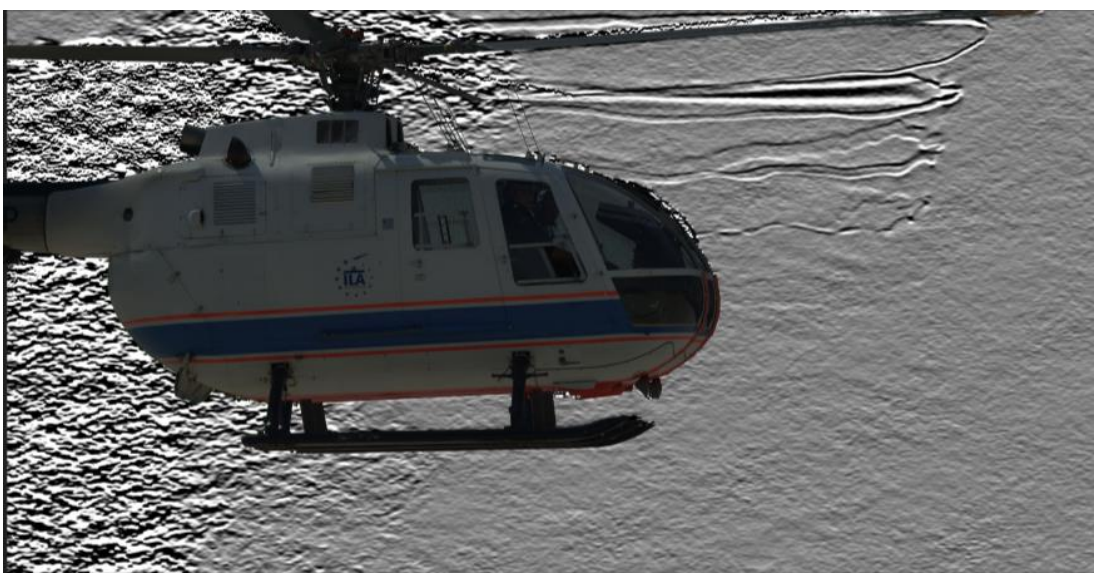

RBOS of a BO-105 in slow forward flight Raffel, DLR Goettingen 


\section{The BOS Method}
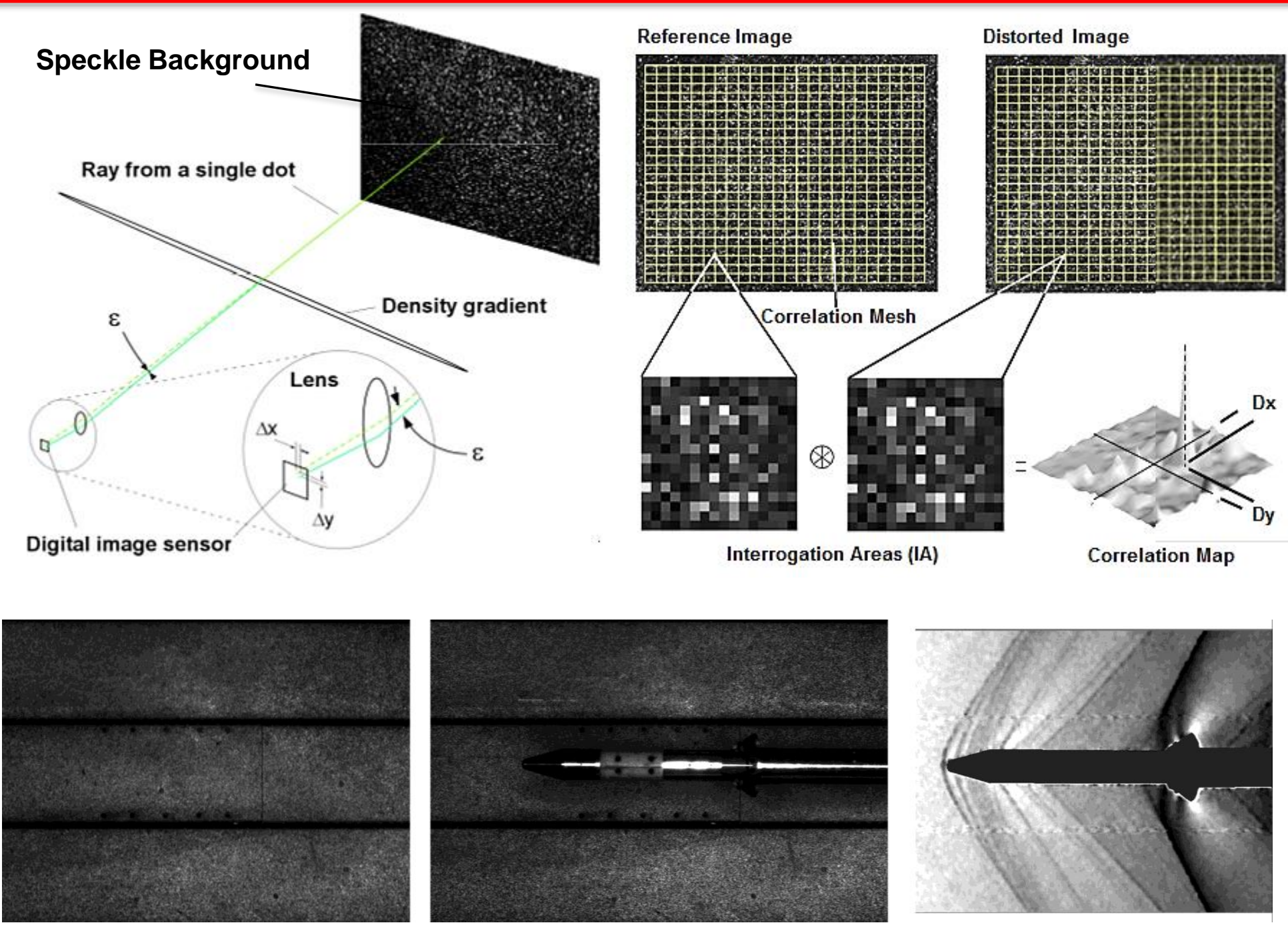

Wind tunnel reference, data image and result of an abort motor tower at $M=1.3$ 

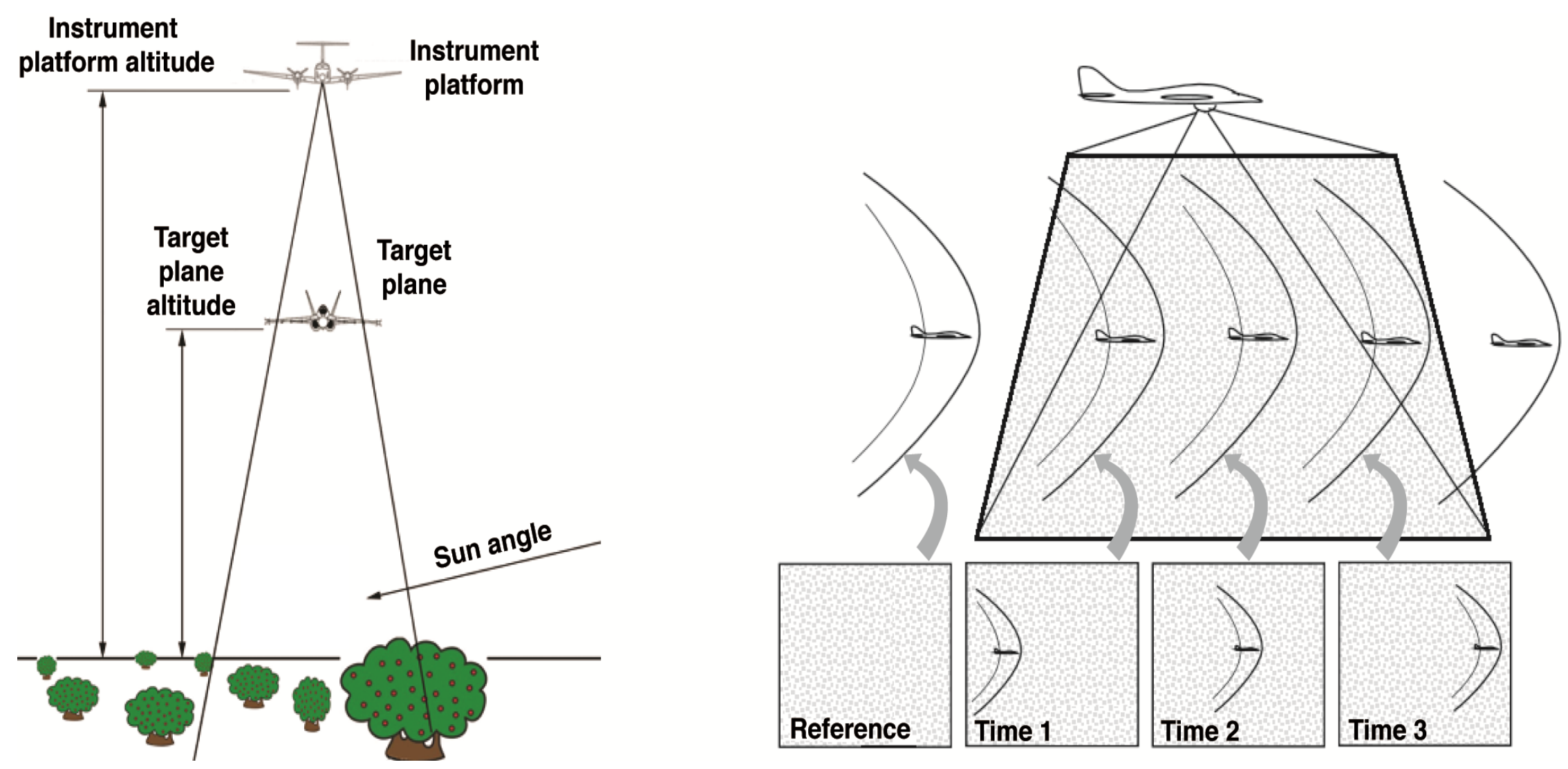


\section{AirBOS Implementation}

- Fly in the Supersonic Corridor near Edwards AFB

- Characterize the Mojave Desert flora in the Supersonic Corridor:

Creosote bushes with scattered Joshua trees

- Bushes average 10 feet $(3.1 \mathrm{~m})$ diameter; too few trees to be of concern

- Dark green against light gray soil; red filter enhances contrast

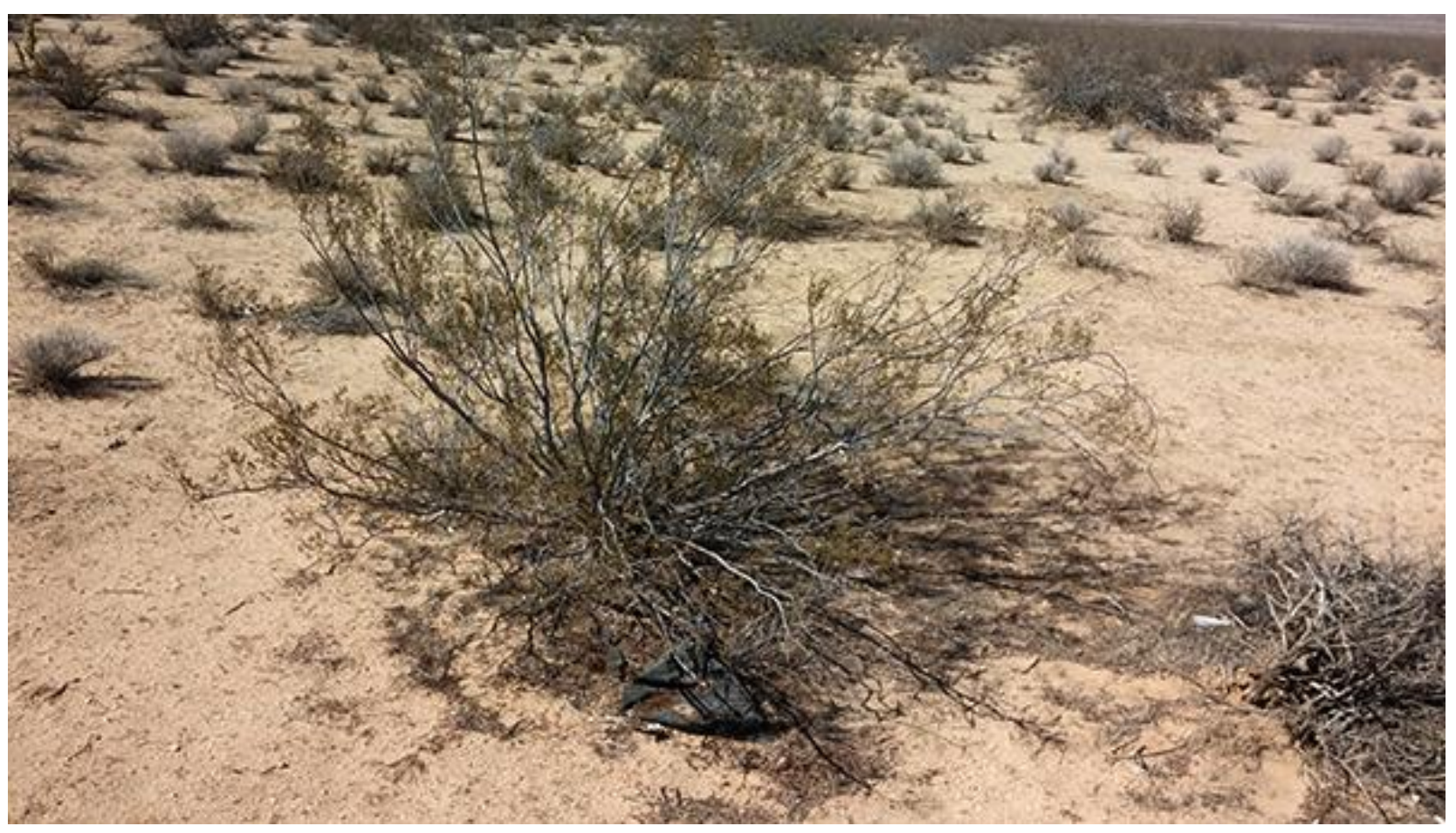




\section{Observer plane}

\section{NASA Beechcraft B-200 Super King Air}

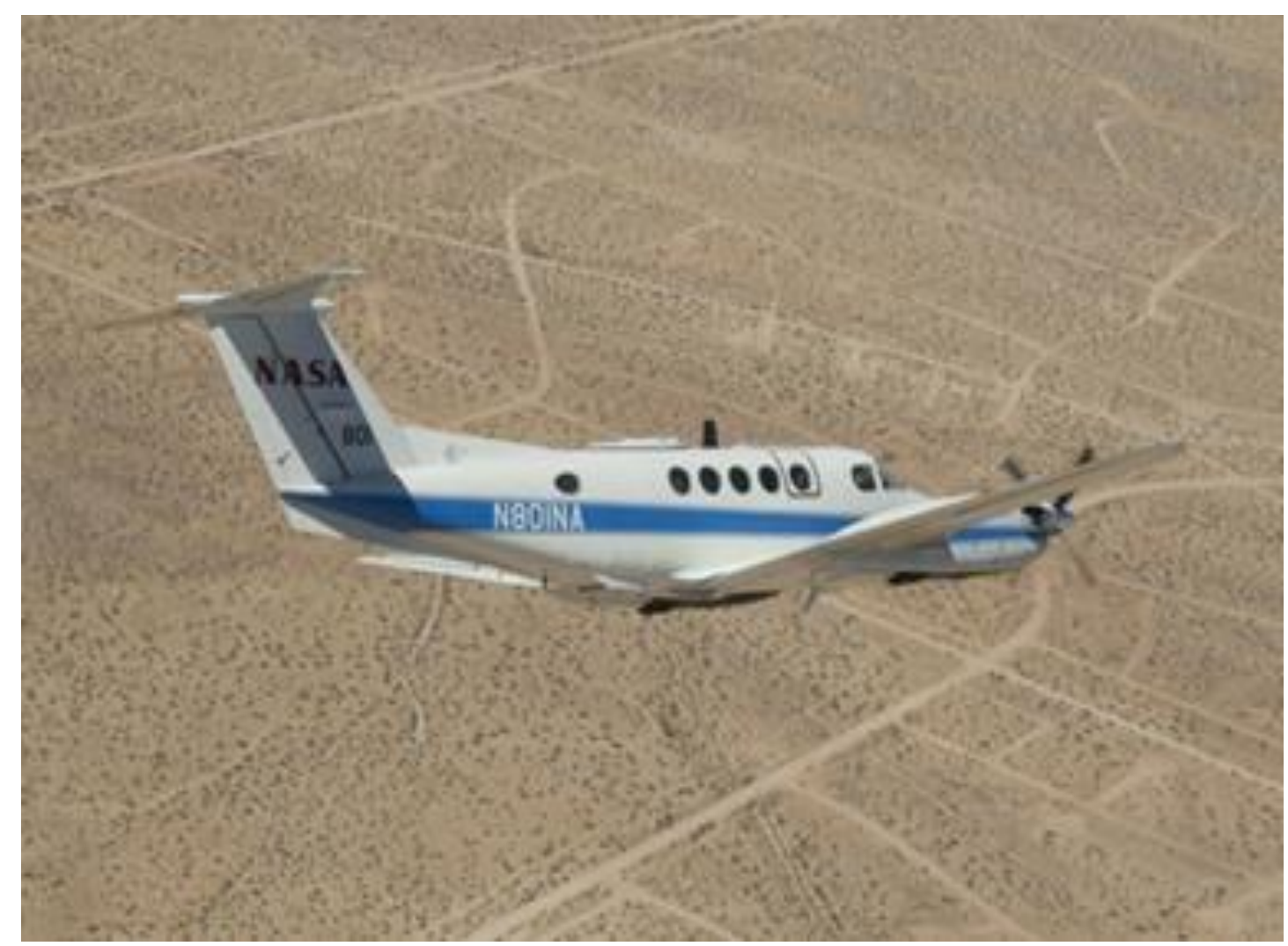

- $\quad$ Fly at 30,000 ft MSL (Highest practical altitude)

- $\quad$ Low stall speed - 90 knots (75 knots at full-flap)

- $\quad$ Already equipped with high-quality nadir port window

- $\quad$ GPS navigation 


\section{Target plane}

Air Force T-38, operated by the Test Pilot School at Edwards AFB

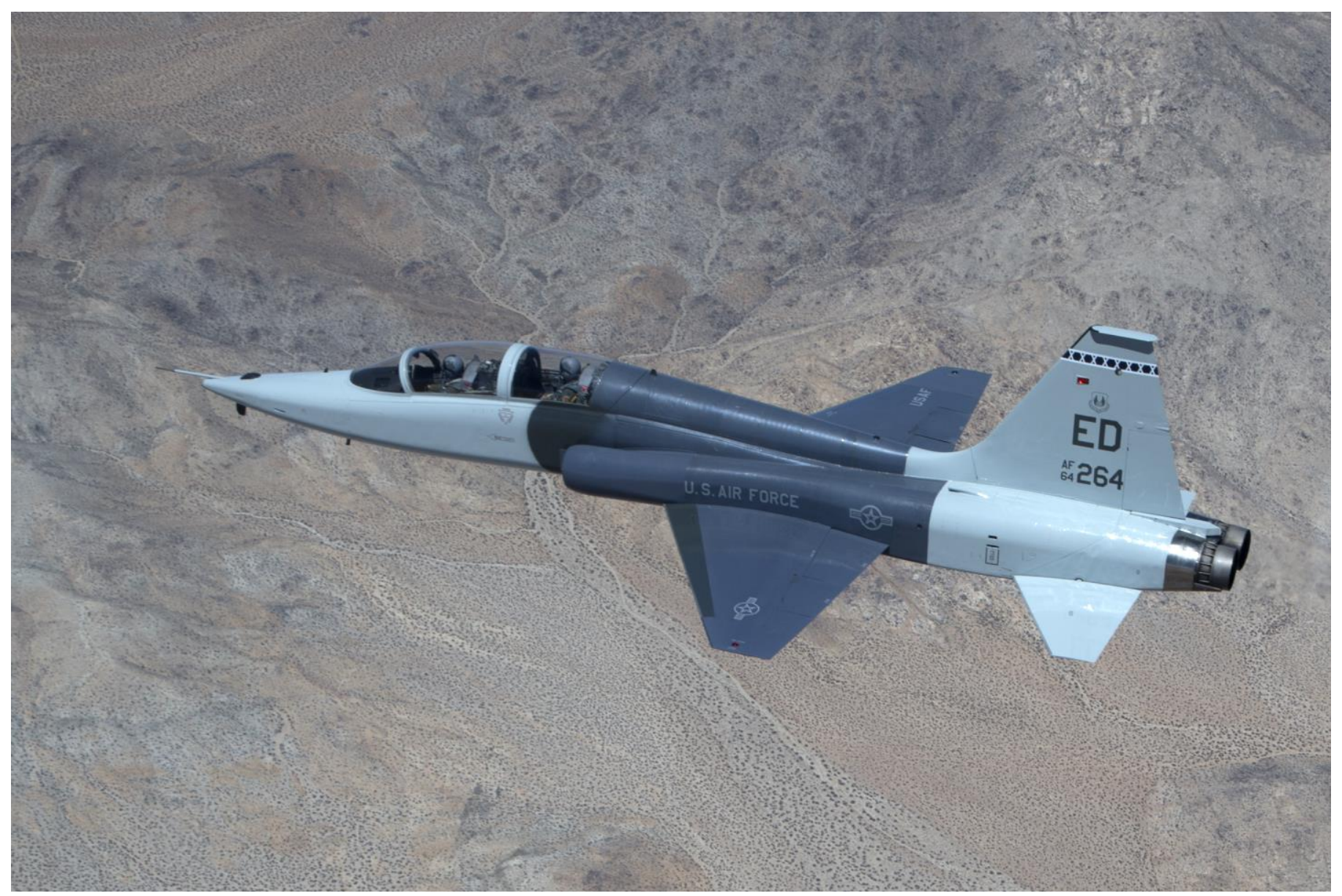

Supersonic flight achieved by full acceleration during a shallow dive, leveling for the flyby 


\section{Imaging system design}

- Calculate the proper lens focal length to optimize speckle size

- Phantom V641, with 2650 x 1600 pixel and 10 - micron pitch

- Speckle distribution should be 2-5 pixels

- Spreadsheet calculates pixel resolution and field of view on ground and at target location

\begin{tabular}{|c|c|c|c|c|c|c|c|c|c|c|c|c|c|c|}
\hline \multirow[b]{2}{*}{$\begin{array}{l}\text { Lens } \mathrm{fl} \\
(\mathrm{mm})\end{array}$} & \multirow[b]{2}{*}{$\begin{array}{l}\text { ccd nx } \\
\text { (pixels) }\end{array}$} & \multirow{2}{*}{$\begin{array}{l}\text { Camera } \\
\text { ccd ny } \\
\text { (pixels) }\end{array}$} & \multirow[b]{2}{*}{$\begin{array}{c}\text { pixel size } \\
(\mu \mathrm{m})\end{array}$} & \multicolumn{2}{|c|}{ Half Angles } & \multicolumn{3}{|c|}{ Altitudes } & \multicolumn{3}{|c|}{ FOV at Target Aircraft } & \multicolumn{3}{|c|}{ FOV at Ground } \\
\hline & & & & $\begin{array}{c}X \\
\text { (Deg) }\end{array}$ & $\begin{array}{c}Y \\
\text { (Deg) }\end{array}$ & $\begin{array}{c}\text { Observer } \\
\text { a/c } \\
\text { (Ft) }\end{array}$ & $\begin{array}{l}\text { Target } \\
\text { a/c } \\
\text { (Ft) }\end{array}$ & Ratio & $\begin{array}{c}\Delta x f o v \\
(F t)\end{array}$ & $\begin{array}{c}\Delta y f o v \\
\text { (Ft) }\end{array}$ & $\begin{array}{l}\text { Resolution } \\
\text { (pixels/ft) }\end{array}$ & $\begin{array}{c}\Delta x \text { fov } \\
\text { (Ft) }\end{array}$ & $\begin{array}{c}\Delta \text { yfov } \\
\text { (Ft) }\end{array}$ & $\begin{array}{l}\text { Resolution } \\
\text { (pixel / ft) }\end{array}$ \\
\hline 105 & 640 & 512 & 25 & 4.36 & 3.49 & 27000 & 13500 & 0.5 & 2057.14 & 1645.71 & 0.31 & 4114.29 & 3291.43 & 0.16 \\
\hline 180 & 2560 & 1600 & 10 & 4.07 & 2.54 & 0000 & 26000 & 7 & 568.89 & 355.56 & 4.50 & 4266.67 & 2666.67 & 0.60 \\
\hline 180 & 60 & 1600 & 10 & 4.07 & 2.54 & 30000 & 28000 & 0.9 & 284.44 & 177.78 & 9.00 & 4266.67 & 2666.67 & 0.60 \\
\hline
\end{tabular}

Sample of table for two cameras and target aircraft separation distances 


\section{AirBOS Implementation}

- Survey the Black Mountain SS Flight Corridor at 30,000 ft altitude

- Photographically survey large area, find consistent flora

- Test for cross correlation performance

- Design flight pattern to hit the "sweet spot" where the acceleration can be achieved, but turn around is within the corridor

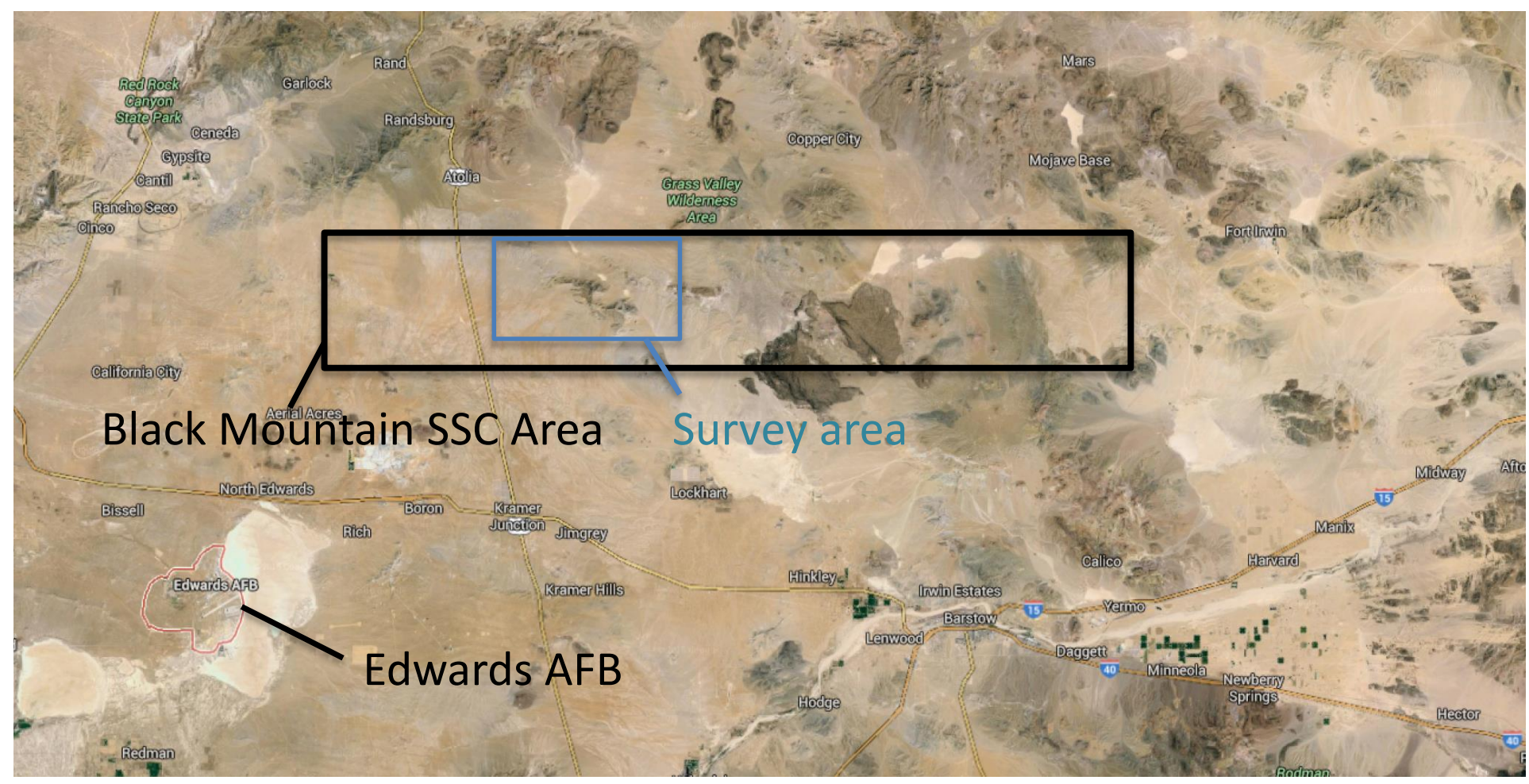

Google Earth view of area of Supersonic Corridor and Edwards AFB 


\section{Determining the Sweet-spot}

Evaluate two successive frames from the reconnaissance flight using cross correlation 


\section{Determining the Sweet-spot}

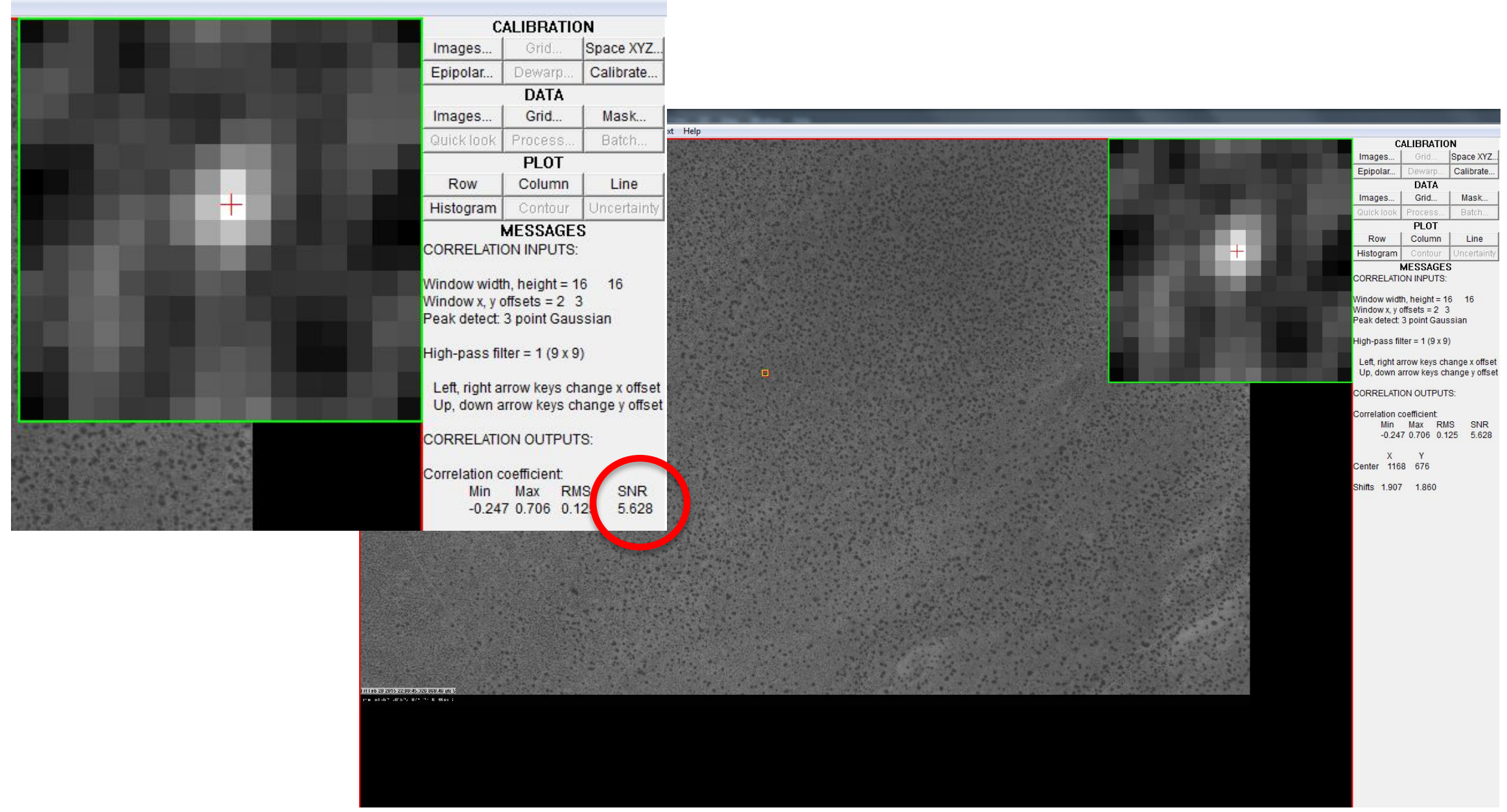

Assure SNR of 5 or higher in the cross-correlation product using the anticipated window size 


\section{Flight Plan}

Ridgecrest

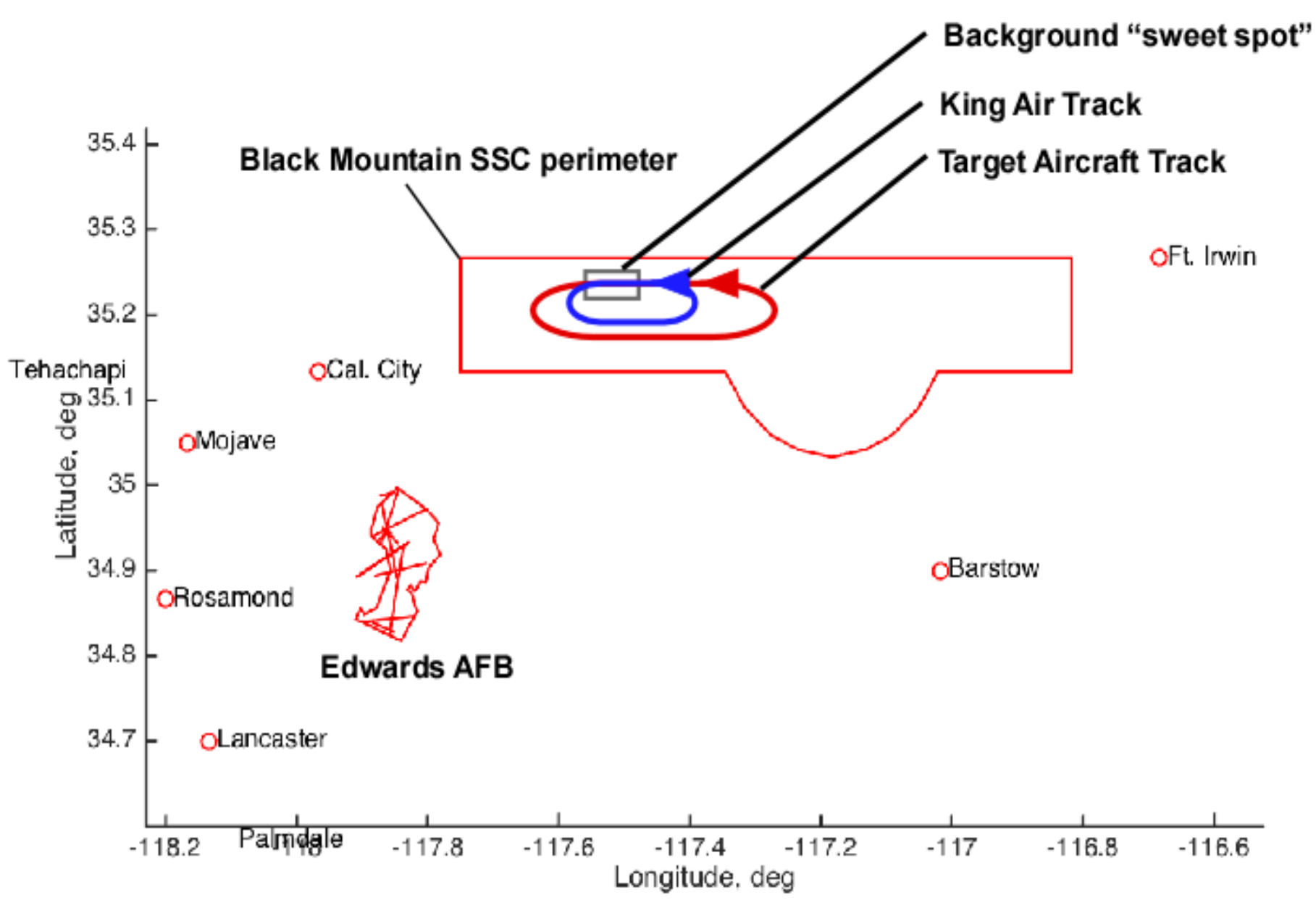




\section{Cameras and Layout}

Phantom V641 monochrome, $2560 \times 1600$ pixels, 10 micron pitch, $180 \mathrm{~mm}$ lens

- 8 GB of internal memory, 2 seconds of record time @ $1000 \mathrm{fps}$

- \#25 Red filter, enhance contrast of bushes against the bright soil

Two cameras: redundancy and potential for stereo and multi-stream referencing

Legacy camera for 2011 work: Goodrich SUI SU640-SDWHVis-1.7RT InGaS

- 640 x 512 pixel sensor, 25 micrometer pixel pitch, and fitted with a 105 mm lens

- Used mainly as real-time spotting camera

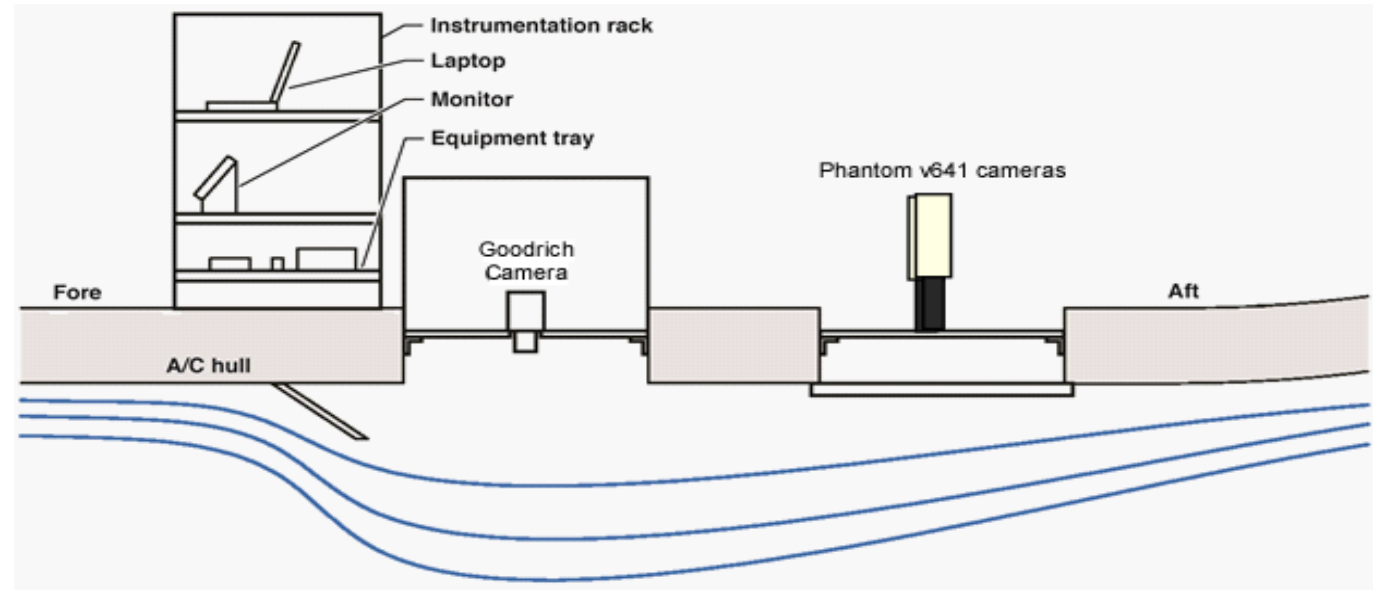

Schematic of cabin layout

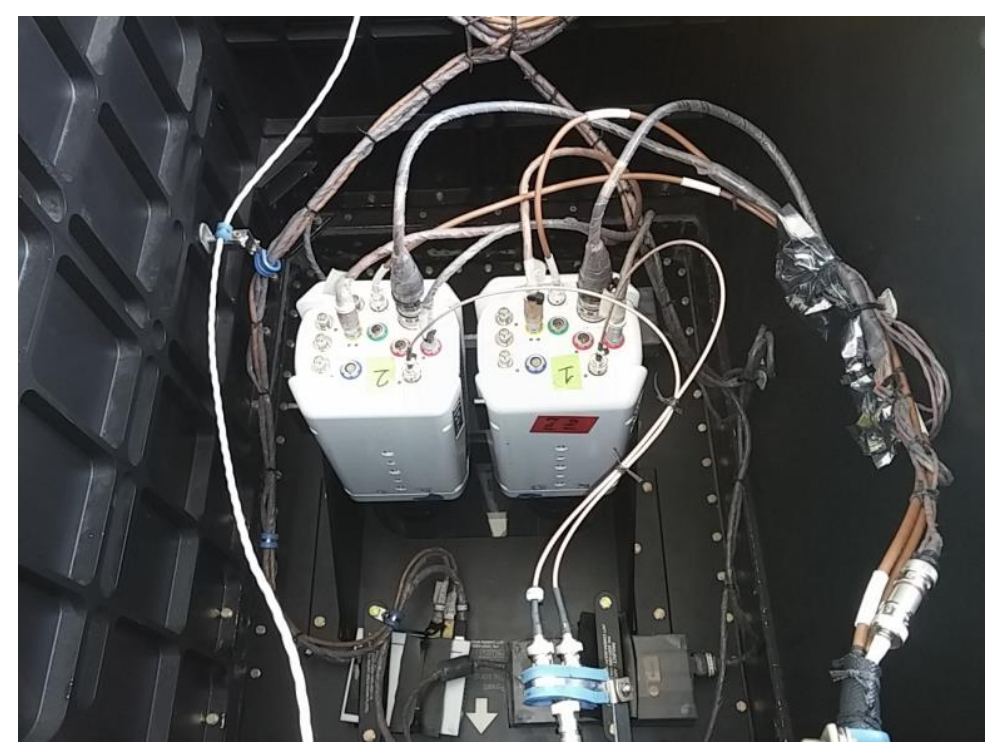

Two cameras, mounted vertically 


\section{Data Processing}

1. Reference-to-data registration: First-order projective transform

- Aligns the displaced backgrounds caused moving observer

- Corrects perspective distortion caused by pitch and roll during acquisition

$$
\begin{aligned}
& x=\frac{a_{1} x^{\prime}+a_{2} y^{\prime}+a_{3}}{c_{1} x^{\prime}+c_{2} y^{\prime}+1} \\
& y=\frac{b_{1} x^{\prime}+b_{2} y^{\prime}+b_{3}}{c_{1} x^{\prime}+c_{2 y^{\prime}+1}}
\end{aligned}
$$

- Four points at corner of images are chosen, large-window CC performed

- Cross correlation between the two images yields $\Delta x$ and $\Delta y$ at each location, $x^{\prime}$ and $y^{\prime}$ are solved to then calculate the eight coefficients

$$
\begin{aligned}
& x^{\prime}=x+\Delta x \\
& y^{\prime}=y+\Delta y
\end{aligned}
$$

2. Image cross correlation at defined grid nodes yields Dx and Dy due to density gradient shift 


\section{AirBOS Results}




\section{AirBOS Results}

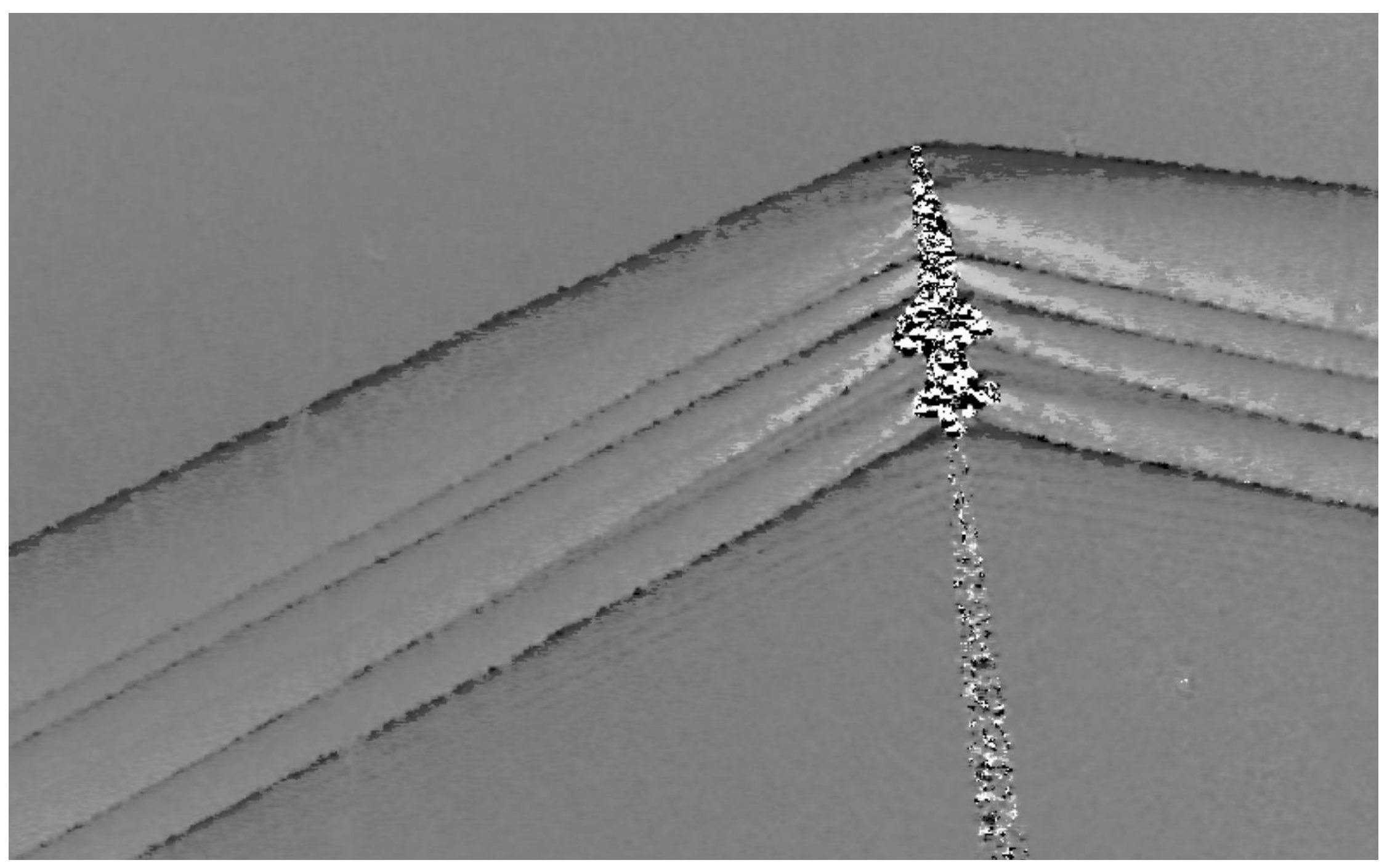

$T-38$ at 45 deg. roll, $M=1.05$, single frame, cross correlated to reference image 


\section{AirBOS Results}

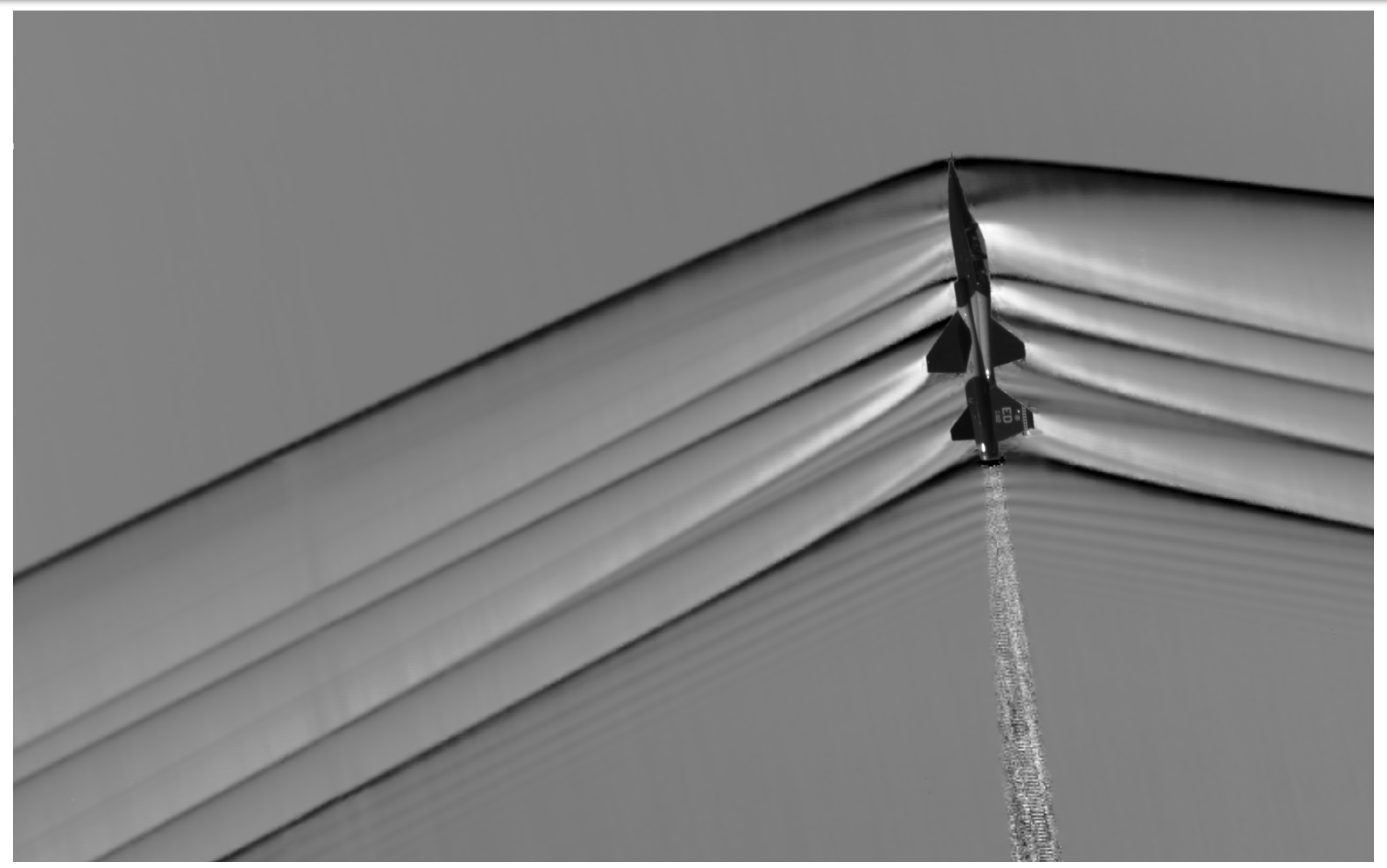

Results from 200 sequences aligned and averaged 


\section{Optical Flow: A new refinement}

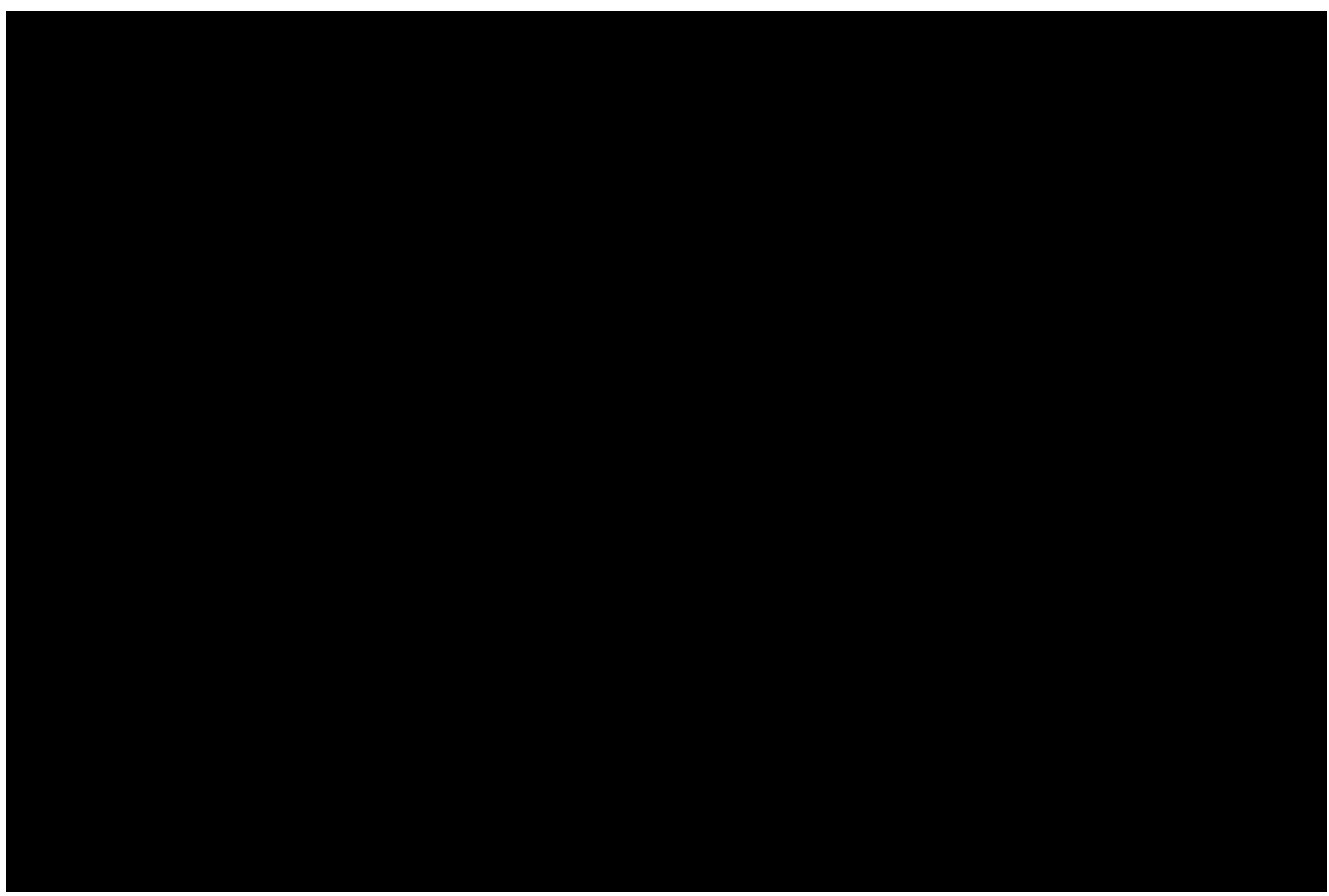

Movie of Optical flow-processed sequence, two frames skipped for brevity 


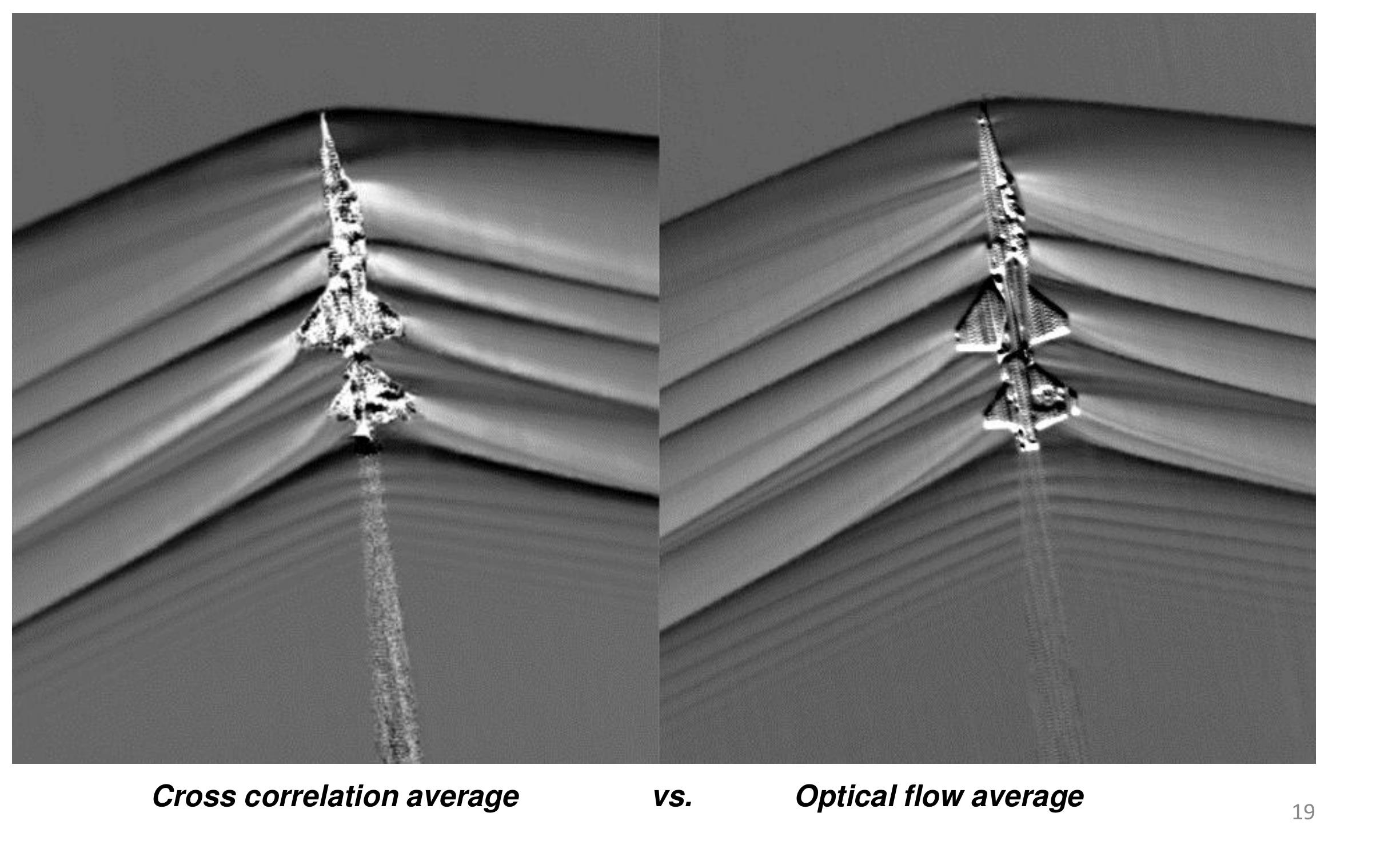




\section{AirBOS Results}

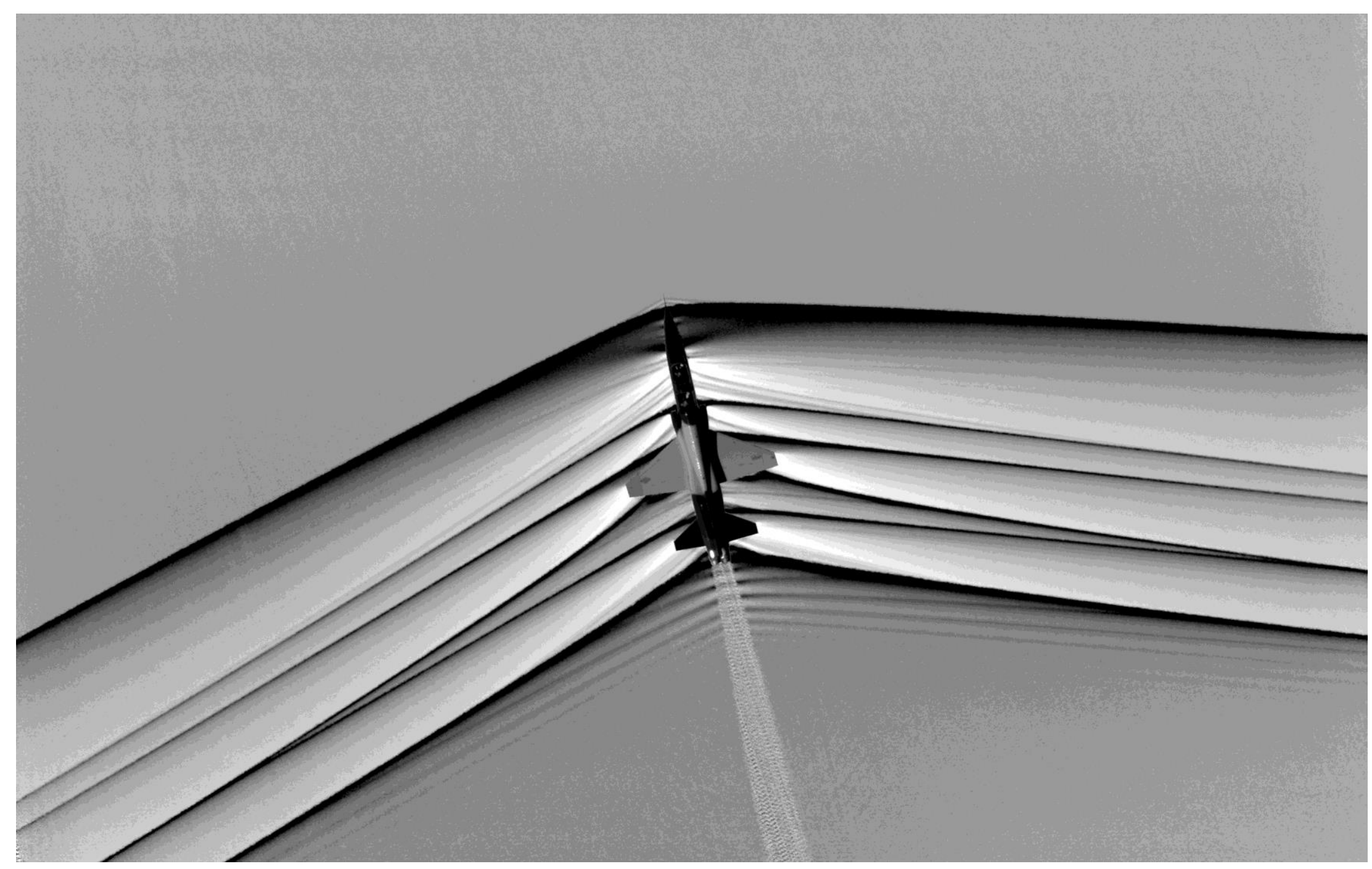

T-38 at Mach=1.05, wings-level optical flow with 100 sequences aligned and averaged 


\section{Summary}

Background Oriented Schlieren has been successfully adapted to full-scale supersonic flight

The planning and system design permit predictable results

Image processing has made the data of high quality - better than wind tunnel data

Technique permits testing of maneuvers, monitoring tip vortex trajectories, and subsonic wakes 


\section{Acknowledgements}

Nils Larson, NASA Armstrong Chief Pilot and the flight crews

Maj. Jonathan Orso and Maj. Jeremy Vanderhal, Instructor Pilots from Air Force Test Pilot School

Brett Pauer, for flight test management

Peter Coen for years of support for this research

Neal Smith and Mike Hill for development of the Optical Flow algorithms 